\title{
A Novel Approach for Improving Quality of Learning Environment in Technical Institutions
}

\author{
Ajinkya S. Joshi ${ }^{1}$, Keshav N. Nandurkar ${ }^{2}$, Padmakar J. Pawar ${ }^{3}$ \\ ${ }^{1,2,3}$ K. K. Wagh Institute of Engineering Education and Research, Nashik, Maharashtra, India \\ 12ajinkya_j@rediffmail.com \\ ${ }^{2}$ keshav1965@gmail.com \\ 3.pjpawar1@rediffmail.com
}

\begin{abstract}
The premier regulatory bodies for technical education in India have mandated several services and facilities for the students of technical institutes. These services and facilities not only help in improving the learning environment in an educational institute but also boost the morale of students thereby enhancing the brand image of the institute. In India, the private un-aided technical institutes do not receive any direct financial support from the government for their day to day working. Considering the limited resources at their disposal, the management of the un-aided technical educational institutes may find it difficult to upgrade all services and facilities simultaneously. It is therefore necessary to shortlist services and facilities that need immediate attention and determine the proportion in which the available budget should be utilized for these services and facilities.
\end{abstract}

A two stage survey was designed and opinion of 1090 students was collected through Google Form. Out of the 14 services and facilities extended by the institute, 4 were shortlisted with the help of first survey. Data collected through second survey was used as a basis for determining the values of attributes. TOPSIS method was then employed to prioritize the shortlisted services and facilities. Finally fund allocation was calculated for every attribute.

\footnotetext{
Ajinkya S. Joshi

I/C Registrar,

K. K. Wagh Institute of Engineering Education and Research, Nashik, Maharashtra, India

ajinkya_j@rediffmail.com
}

Results indicate that in the opinion of the students, quality of the mess is the most significant issue and necessitate maximum fund allocation. Parking appears to be the least significant issue and hence minimum funds can be allotted for this aspect.

The analysis is based on the facilities extended by the institute and opinion of the students. A similar exercise can be extended to any educational institution or organization with suitable modifications.

The study is unique and serves as a guideline to the management of private un-aided technical institutions in fund allocation. This study is an attempt to present a novel approach for improving quality of learning environment in un-aided technical institutes.

Keywords: Student facilities; Quality learning environment; Un-aided technical institutes; Multicriteria decision making (MCDM); Weight determination; Fund allocation; AHP; PROMETHEE; TOPSIS.

\section{Introduction}

A learning environment refers to the sum of all services and facilities that help in enhancing the ability of the students to learn. The motive of extending various services and facilities is to assist, stimulate and facilitate the instructional process. These services and facilities contribute directly and indirectly to the teaching-learning process (Dada et 
al., 2018). The interior design of the facilities makes these places more functional, healthier, and enjoyable thereby improving the learning environment and confidence of the users (Obeidat and Al-Share, 2012).

The institutes providing higher education can be broadly categorized into two types namely institutes providing non-professional education and professional education. The admission to the nonprofessional courses is generally based on the marks obtained by the students in the qualifying examination. On the other hand the admission for the professional institutes is normally based on the State or National level Common Entrance Test (CET) in addition to the other eligibility criteria. Therefore normally majority of the students getting admitted in the non-professional courses are either local or from the same region while a significant number of nonlocal students are admitted in any professional course. Before seeking admission, the students staying at far off places primarily tend to look out for the services and facilities provided by the institutes. As such the services and facilities provided by any professional instituteassumes greater significance. The inadequate facilities may affect the mental and physical health of student leading to poor academic performance by him/her.

The professional educational institutes in India strive to extend various services and facilities to their students. It should be noted that All India Council for Technical Education (AICTE), New Delhi and Directorate of Technical Education (DTE), Maharashtra State, India has mandated several services and facilities for the students of technical institutes. The monitoring of these services and facilities is undertaken by accreditation agencies such as National Accreditation and Assessment Council (NAAC) and National Board of Accreditation (NBA) as well as and the affiliating University.

The unaided technical institutes in the State of Maharashtra, India do not receive any direct financial support from the Central or State Government. These institutes manage their day to day working from the fees collected from the students. Naturally the unaided institutes cannot afford providing every service free of cost to the students. However to boost the morale of the students and enhance the institute image, it is also necessary to provide quality services and facilities at a minimal cost.
Every technical institute starts with a basic infrastructure and facilities but considering the limited resources at their disposal, the management of the unaided technical educational institutes may find it difficult to upgrade all services and facilities simultaneously. It is therefore necessary to prioritize the services that need to be upgraded and determine fund allocation for different components within a selected service. This study is an attempt to present a step by step approach to enhance the quality of learning environment in an educational institution. This approach will serve as a guideline for upgrading student services and facilities in other educational institutes.

\section{Literature Review}

A student is the keystone of any educational institute. Success of any educational institution largely depends on the performance and placement of the students. It is necessary to provide quality services and facilities to boost the student morale, improve student performance and thereby enhance the brand image of the institute. Satisfied students in turn will lead to attracting students of higher merit in the institute.

Tsedzah and Obuobisa-Darko (2015) carried out a research in a private University of Ghana to find out the level of student satisfaction with the services and facilities provided by the University. Opinion of 428 students was collected and analysed using Statistical Package for Service

Solutions (SPPS). Results revealed that students satisfaction with academic experiences and general satisfaction was significant but moderate and higher than the satisfaction for academic support services. Weakest level of satisfaction was observed in student services. Researchers also collected suggestions from the students for improving the services and student satisfaction.

Choudhury (2015) undertook a research to address the issue of service quality in higher education sector. Opinion of 1152 students from six higher educational business schools in India was obtained and analysed. The analysis of the 30 items comprising different aspects of service quality revealed that customers distinguish four dimensions namely competence, tangibles, responsiveness and convenience. The performance of the six Higher Educational Institutes 
(HEI's) was compared against the four service quality dimensions obtained from the factor analysis. TOPSIS was employed to evaluate, compare and rank the HEI's. The dimensions namely competence and tangibles were observed to be the most important service quality factors in the context of business management education in India.

Maddock et al. (2005) carried out a survey to examine the characteristics of food services in primary and secondary Victorian schools. Responses about school canteen operating procedures, food policies, staff satisfaction and desired additional services were collected from 150 primary and 208 secondary schools. The data were analysed by frequency and two by two cross tabulation analysis. More primary schools were satisfied with the school food services than the secondary schools. It was observed that secondary schools were more interested in the additional services. Results also revealed that most of the schools expressed satisfaction with the nutritional status of the food served in the canteen.

Hostel is one of the important factors affecting the overall academic performance of on-campus students in institutions of higher learning. Philip et al. (2018) conducted a study to assess the facilities in hostels of federal Universities in North Central Nigeria. Responses obtained from 180 students were analysed using SPSS software. Overall opinion of students revealed that the overall condition of the hostels was not satisfactory and that it required immediate attention. The research points out that certain problems such as overcrowding in rooms, non availability of recreational spaces and lack of internet services are some of the challenges in hostels. The study also recommends a periodic post occupancy evaluation of facilities in federal University hostels.

Anthony Reale (2000) conducted a research in a midsized University located in Western New York State. The purpose of the study was to determine gaps betweenstudent's expectations, needs and wants and what the students actually receive from the dinning services. Questionnaire survey was obtained from 67 undergraduate students at dinning centres in three different campuses. Based on the responses, some gaps were observed between the actual and expected service quality of the dinning service. The researcher has also provided some suggestions to address the customer expectations. These include developing a well focused service strategy to enhance satisfaction, empowering employees and impart training to the employees to provide personal interaction and quality service to the customers.

In India, free and compulsory Education to children from six to 14 year age group is provided under the Sarva Shiksha Yojana of the government. A research was undertaken in four districts of Gujarat to assess the effectiveness of transportation and escort facility extended to primary school students residing in remote and interior areas (Patel et al., 2014). The objective was to study the impact on the regularity, retention and academic performance of the students. The study also collected the opinion of teachers, parents and school management committee members about the initiative. Findings of the study reveal that the transport facility helped to increase the attendance of the students and was more effective for students up to standard VI. However no impact of the transportation facility was observed on the retention and academic performance of the students.

Researchers have conducted several studies evaluating the influence of different services and facilities on the performance of the students (Singh and Kumar 2017; Godstime and Joseph 2019; Musa and Baharum 2012; Odeh et al. 2015; Isa et al. 2017; Nepal and Maharjan 2015; Nepal 2016). Research on impact of specific facilities on the students has also been undertaken in the past. Some of these include impact of internet facilities (Moate et al. 2017; Selvaraja et al. 2014), library facilities (Chaubey and Manglik 2017; Rani 2018) and student services (Ciobanu 2013; Kaur 2016; Stewart et al. 2013; Coskun 2014).

By way of employing different mathematical tools, researchers have presented the impact of services and facilities or some specific facilities on the learning environment. In contrast, the present study has made an attempt to develop an approach for enhancing the learning environment in an educational institution. The developed approach has been successfully extended to a technical un- aided institution and results have been presented as a case study. Such an initiative will be of immense help especially to private and unaided institutes where financial resources are limited.

\section{Methodology}

There are more than 350 unaided engineering institutes in the state of Maharashtra, India. A reputed unaided engineering college from the state of 
Maharashtra, India was selected for the study and the data were collected from undergraduate and post graduate students of engineering, Master of Business Administration (MBA) and Master of Computer Applications (MCA) courses.

In the present study, IT tools (Google Forms) have been used to collect data from the students of the institute. Response obtained by employing this method is transparent, impartial and accurate as the researcher is not in direct contact with the respondents (Shahabadkar et al., 2019). The respondent is free to respond as per his/her convenience. However regular follow up with the respondents is necessary.

A two stage survey using Google Form was designed for the students of the institute. The link for the first stage was circulated to all undergraduate and postgraduate students of the institute through e-mail and social media. Out of the 4000 plus students of the institute, responses were obtained from 1090 students over a period of 20 days. Participants of the survey included students residing in institute hostel, students utilizing own means of transport for reaching the institute and those availing the transport facility of the institute The characteristics of the participants are shown in table 1.

Table 1 : Characteristics of participants

\begin{tabular}{lc}
\hline \multicolumn{1}{c}{ Participant characteristics } & Value \\
\hline Age group & 17 to 22 years \\
Sex ratio (Male : Female) & $63: 37$ \\
Average annual householdincome & 5 to 10 lakhs (INR) \\
Average merit & Top $30{ }^{\%}$ (CET score) \\
Urban : Rural students ratio & \\
Percentage of FE/SE/TE/BE/PGstudents & $32: 18: 19: 22: 9$ \\
Ratio of Non-Hostellite :Hostellite students & $71: 29$ \\
\hline
\end{tabular}

In the first stage of the survey, students were asked to rate the 14 institutional facilities on a scale of ten where ten represented best performance. These 14 facilities included canteen, central library, training placement cell, internet- Wi-fi, gymkhana-sports, students section, accounts section, examination section, banking, hostel, mess, transport, parking and medical. The institute intends to upgrade and improve all facilities provided to the students. However, it is advisable to shortlist and concentrate on those facilities that require more attention from the student's point of view. Average value of the student responses for every facility was calculated and facilities obtaining average value less than seven on the ten point scale were shortlisted. The fourfacilities obtaining score less than seven were internet, hostel, mess and parking.

The second stage of the survey was initiated immediately after the conclusion of the first survey during the last month of the first semester and this stage lasted for another 25 days. This survey was circulated amongst the students participating in the first survey through e-mail and social media. Responses for the second stage were obtained from 666 students of the institute. The second stage of the survey focused on improvements required within every shortlisted facility. Around six to seven sub criteria were considered for every shortlisted facility. The sub-criteria for every shortlisted facility are provided in Annexure. Researchers have pointed out that a five point likert scale increases the response rate, quality of the responses and also reduces the frustration level of the respondents (Babakus and Mangold, 1992). Hence students were asked to rate improvement required for every sub criteria on a scale of five where five represented maximum need for improvement. Students were also permitted to suggest any additional improvement required for every facility.

Several scientific methods are available for determining percentage contribution and ranking of the attributes. The current study employs a well known multi- criteria decision making (MCDM) technique - The Technique for Order of Preference by Similarity to Ideal Solution (TOPSIS). This technique functions by comparing criteria Vs criteria with respect to every alternative (Joshi et al., 2019). The result will help to determine the priority of the selected alternatives, proportion of fund allocation between different criteria of selected alternatives and actual fund allocation for every criterion.

The steps involved in the application of TOPSIS are discussed as under:

Step 1: Identifying evaluation attributes In the first step key attributes are identified and based on the available data, an evaluation matrix is prepared.

Step 2:Creating evaluation matrix and obtaining a normalized decision matrix

An evaluation matrix consisting of $m$ alternatives and ncriteria is prepared. The intersection of every 
alternative and criteria is given as $\mathrm{xij}$. The normalized evaluation (decision) matrix is prepared using the following equation:

$$
R_{i j}=\frac{x_{i j}}{\sqrt{\sum_{j=1}^{M} x_{i j}^{2}}}
$$

wnere

$$
1=1, L, \ldots . . m \text { ana }
$$$$
\mathrm{J}=\mathrm{I}, L, \ldots \mathrm{n}
$$

Step 3: Obtaining weighted normalized matrix

The weighted normalized matrix is obtained by multiplying normalized decision matrix by the assigned weight. In the study, it was assumed that all criteria are equally important. Hence equal weights $(0.25)$ were assigned to every criterion. Equation for the weighted normalized matrix is as follows:

$$
V_{i j}=w_{j} x R_{i j}
$$

where $\mathrm{i}=1,2, \ldots . \mathrm{m}, \mathrm{j}=1,2, \ldots . \mathrm{n}$ and $\mathrm{w} \mathrm{j}$ represents weight of the $j$ th attribute.

Step 4: Calculating the positive ideal $(\mathrm{V}+)$ and negative ideal $(\mathrm{V}-)$ solution

The values for positive ideal solution (PIS) and negative ideal solution (NIS) are then calculated using the following equation:

$V^{+}=\left(V_{1}+, V_{2}+, \ldots, V_{n}+\right)$ maximum values and

$V^{-}=\left(V_{1}^{-}, V_{2}^{-}, \ldots, V_{n}^{-}\right)$minimum values

Step 5: Calculation of separation measures using ndimensional Euclidean distance

Thereafter the separation of every alternative from the positive ideal solution (PIS) and negative ideal solution (NIS) is carried out as follows:

$$
\begin{aligned}
S_{j}^{+} & =\sqrt{\sum_{i=1}^{n}\left(V_{i j}-V_{i}\right)^{2}} \quad \text { and } \\
S_{j}^{-} & =\sqrt{\sum_{i=1}^{n}\left(V_{i j}-V\right)^{2}}
\end{aligned}
$$

where

$$
\mathrm{j}=1,2, \ldots, \mathrm{N} \text {. }
$$

Step 6: Calculation of closeness coefficient (P) and percentage contribution

Using separation values of PIS and NIS, closeness coefficient is calculated with the help of following equation:

$$
P_{j}=\frac{S_{j}^{-}}{S_{j}^{+}+S_{j}^{-}}
$$

Finally percentage contribution of every alternative is calculated using following equation:

$$
P C_{j}=\frac{P_{j}}{\sum P_{j}} \times 100
$$

The evaluation matrix prepared in the first step of the TOPSIS methodology was used to determine the proportion of fund allocation for every attribute. This was achieved by dividing the value of individual attribute by summation of attribute for every given element/ alternative of the evaluation matrix.

The percentage contribution of each alternative was then used to determine the actual fund allocation for every attribute. The actual fund allocation for every attribute of a given element / alternative was calculated by multiplying the proportionate fund allocation of every attribute with the percentage contribution of respective element/ alternative.

\section{Proposed approach}

A six step approach has been developed to suggest the distribution of available funds amongst various components within a selected service or facility. This approach is discussed as follows:

4.1 Identification of appropriate facilities affecting learning environment

As discussed in section 2, researchers have evaluated the impact of several services and facilities on the learning environment of the students. Although these do not form the part of the actual teaching process, they exert a considerable influence on the learning process. In the first step, it is therefore necessary to identify every such service or facility that needs to be extended to the students. These services and facilities include sanitation, potable water, 
transportation, medical, gymnasium and sports, canteen, mess, library, training and placement, accounting, documentation support, internet, hostel, mess, banking, examination, safety measures, parking and so on.

It should be noted that institutes cannot afford to provide every service free of cost to the students. Since the main motive of any educational institute is to provide quality education, some of the services may be provided at a minimal cost. The main aim to extending these services and facilities is to ensure that the students are comfortable in the campus and will be able to focus and excel in the academics. Selection of services and facilities affecting the learning environment will depend on the institute under consideration.

So far as the current research is concerned, services / facilities provided by the institute under consideration are discussed below:

\subsubsection{Canteen}

A canteen is a place where eatables are served to the students and staff at a price. An institution uses a canteen to meet the nutritional needs of the students and staff so that they obtain energy to accomplish the daily task (Norman 2019). A canteen also serves as an informal meeting place for the students. Students of different caste, creed and race sit and share a table thereby overcoming social barriers. Adequacy of infrastructural and human resources is important for providing quality service in the canteen (Weerasinghe, et al. 2017). The institute has outsourced the canteen facilities and ensured that all eatables are sold at a reasonable price. Adequate space, infrastructure and other necessary facilities have been provided. Emphasis has been given on the quality of the food served at the canteen. Students and staff may carry their own food stuff or order food from canteen.

\subsubsection{Central library}

A library is the heart of any educational institute (Newmon and Sengar 2013; Kannappanavar and Jayaprakash 2014). Library is the strength of any educational institute and contributes to the progress of the institute (Lohar and Kumbhar 2002). The library of the institute is located in a separate module and is accessible to all departments of the institute. The library has a rich collection of more than 91000 books and subscribes to nearly 270 national and international journals, magazines and e-journals. The total allotted area for the three storey library is about 16000 sq. ft. Besides e-library, NPTEL video lectures, membership of other libraries, remote access platform and e-book reader are some of the facilities available for the staff and students. The library is open for twelve hours during week days. The timing is extended and the library is also kept open on Sundays and holidays during the examination period.

\subsubsection{Training and placement section}

A training and placement (T\&P) cell not only assists the students to choose the right career path but also equips them with required knowledge and skill to face the campus interviews. This cell also helps in meeting the manpower requirements of the industry. The cell needs to be active throughout the year for providing training and placement opportunities to the students (Angadi and Ravanavar 2014). The T\&P cell of the institute is headed by a senior faculty and is well supported by dedicated and committed staff besides departmental training and placement coordinators. A dedicated Wi-Fi enabled infrastructure spreading over 5000 plus sq. $\mathrm{ft}$. has been allotted for the T\&P activity. Infrastructure includes separate cabins for staff, two computer labs, GD room, interview rooms and video conferencing facility. More than 100 companies visit the institute regularly to conduct the recruitment process. For overall development of the students and increase placements, various activities such as career guidance programs, orientation and training programs, expert seminars, workshops, HR Connect, CEO meet; team building and motivational sessions are organized by the cell.

\subsubsection{Internet and Wi-Fi}

AICTE, the apex body for technical education in India, has issued directions on providing internet and Wi-Fi facilities in the technical institutions. Internet and Wi-Fi has become a way of life for majority of the students enrolled in higher education system (Pradeepkumar and Priya 2017). The institute has established a small team under the System Analyst to upgrade the internet speed and provide Wi-Fi facility in the entire campus. The speed of internet in the institute has been increased gradually. Staff and students can log in the system and also access internet over their mobile phone or tab. User account and bandwidth are managed with the help of Cyber Firewall. The institute has a campus-wide fiber optic 
network with High End Central Core switch at the Central Network Centre and caters approximately 6000 users. Almost entire campus is connected by LAN.

\subsubsection{Gymkhana and sports}

Physical activity and participation in sports is utmost important for physical and mental health. It also helps in increasing the concentration of the students. Various competitions are arranged at University, State and National level to boost the morale of the students. The institute has taken adequate efforts for physical wellbeing and promoting sports activities amongst the students. A state-of-theart gymnasium with an area of $639 \mathrm{sq}$. mts. is provided with all necessary advanced equipments. Besides various indoor and outdoor sports facilities, a playground with running track of 20,000 sq. mts. is also available. The institute also encourages the students to participate in intercollegiate, inter zonal, inter university and open tournaments.

\subsubsection{Students section}

A students section is often a neglected area in any technical institute. However providing support for non- academic activities enable the student to concentrate on studies. This is the section with which the student first comes in contact after getting admitted. All original documents of the students are deposited in this section. Various certificates such as fee structure, bonafide, appearing, character, leaving certificate and demand letter are issued by this section. This section also extends support to the students in applying for various online and offline scholarships. The institute has appointed a team of young and dynamic staff for addressing the needs of the students. The institute has implemented Enterprise Resource Planning (ERP) system which simplifies the task of the students section.

\subsubsection{Accounts section}

So far as the students are concerned, the task of accounts section is not limited to collection of fees but includes several other activities. Some of these include follow up with students paying partial fees, collection of breakage charges, stationery charges, providing travelling and dearness allowance to students representing the institute at various forums, process and distribute the institute level merit scholarships, provide custom clearance certificates for import of educational material, process insurance of students, provide advance for various student activities and provide clearance to the pass out or students leaving the institute. Catering to various student activities besides discharging the regular task related to staff and suppliers is a daunting task especially if the number of admitted students is large. More than 4000 students are enrolled in the institute. This has prompted the institute to appoint separate accounts clerks for the students. This section works in liaison with the students section and other academic departments.

\subsubsection{Examination section}

Appearing for the examination and securing good marks is normally the aim of the students. Since the institute is affiliated to the University, it has to follow the examination pattern of the University. At the same time, it also offers one autonomous course thus making the examination system somewhat complex to handle. Besides making necessary provisions for oral, practical, online, in- semester and end semester exams, the section is also involved in other activities. These include filling of the eligibility, examination, revaluation form, issue of mark sheets, certificates, arrange institute level convocation function and most importantly follow up with the University for resolving student related problems. Adequate infrastructure including a separate examination control room, strong room and computing facilities have been provided for the section. The exam section staff members are assisted by College exam officer and departmental exam coordinators during the examination period.

\subsubsection{Banking service}

Providing banking and ATM facilities to the stakeholders is an important aspect for any educational institute. The institute has provided space and infrastructure for two scheduled cooperative banks in the institute building. Although ATM facility is not available in the campus, ATM centre of five different banks are located in the vicinity of the institute building. Students and parents can thus perform all necessary banking transactions with ease. In addition to these banks, a nationalized bank located near the institute also provides necessary support to the students especially in obtaining the scholarships offered by the government. 


\subsubsection{Hostel for boys and girls}

A hostel is a home away from home. It is a shelter to the students coming from distinct places for a particular duration with intent to pursue education (Sharma et al.2018). Hostel life makes the student independent, smart, disciplined, active and share space, facilities with roommates (Khozaei et al., 2010; Suki and Chowdhury, 2015). Lack of hostel accommodation increases absenteeism resulting in poor academic performance (Chiguvi and Ndoma, 2018). The institute has constructed separate hostel buildings with accommodation for 338 boys and 212 girls in the campus. The calm and quiet surrounding provides an ideal environment for pursuing studies. The hotel is looked after by a separate warden. Various recreational facilities are also provided to the students. Separate doctors have been appointed for the boys and girls hostel to take care of the students after office hours and holidays.

\subsubsection{Mess for boys and girls}

The institute provides separate on-campus dining facility for the students enrolled in the boys and girls hostel. This facility includes daily breakfast, lunch and dinner. Learning environment of hostel or mess has significant impact on the quality of learning and hence it is necessary to keep the environment of hostel or mess pleasant (Mondal et al. 2018). Appropriate measures are taken for overall ambience and cleanliness of the mess. Automatic 'roti maker' and other necessary equipments are installed in this mess to ensure that waiting time for students is bare minimum. To bring awareness amongst the students, amount of food wasted on the earlier day is displayed in the mess. The institute has installed machine to prepare composite fertilizer from the waste food material. This fertilizer is utilized for the trees and plants in the campus.

\subsubsection{Institute transport facility}

In view of the increase in traffic volume day by day, it is necessary that students reach the institute safely and in time to prevent academic loss. Parents too feel concerned about the safety and security and therefore tend to send their wards by using public transport system or sign up for the bus facility offered by the institute at least for the first two years. Commutation has a large impact on the environment and further leads to parking issues. Keeping this in mind the institute has established its own transport service exclusively for its students. This bus service covers most of the city areas. A small team looks after the bus admission, scheduling of buses, driver duties, maintenance, breakdown and other related issues. The timings of the bus are adjusted in accordance with the institute timing. Adequate spare buses and drivers are available in case of emergency. No charges are collected from the students when the institute bus facility is utilized for industrial visit. In spite of the increase in the fuel prices over the years, an attempt has been made by the institute to keep the yearly bus fare under control.

\subsubsection{Parking}

The number of students using the institute bus facility or public transport system is less as compared to the total number of students enrolled in the institute. Many students especially those in the third and final year of the undergraduate courses tend to use their own vehicle for commutation. This puts a lot of pressure on the security officials and the infrastructure. Some Universities have been effective in reducing the car users by employing strategies such as limiting the use of parking for faculty and staff, parking discount for bus users, support car pooling and discount for bike sharing (Rotaris and Danielis, 2015). The institute has developed separate parking lots for female staff and students, hostel students, senior faculty and other gent's staff and students. Parking of four wheeler vehicles inside the campus has been restricted to teaching staff. To maintain discipline and security, separate security guards are appointed for every parking lot.

\subsubsection{Medical facilities}

The institute is cautious about the health of the staff and students and has undertaken several initiatives in this regard. A well equipped dispensary (OPD) has been established in the institute building. A qualified doctor provides free consultation and basic medication to the staff and students through this dispensary. As discussed in subsection 4.1.10, separate doctors look after the health of students residing in the hostel after office hours and holidays. The ambulance of the institute is provided free of cost to the staff and students. This ambulance facility is also available after office hours. A regular tie-up (MOU) has been made with nearby hospitals. Discount on consultation and admission is available to the students, staff and close relatives of the staff members in these hospitals. First aid box is provided 
to every department and section. Facilities such as wheel chair, ramp and lift are also available for the physically challenged.

4.2 Obtaining feedback about the existing system through scientific approach

The next step in the process is to ascertain the perception about the services and facilities extended by the institute and additional expectations of the students. A set of questions for every service and facility under consideration may be framed. Large number of questions may cause survey fatigue and hence reduce the response rate. The survey should therefore include minimum number of questions. Alternatively, services or facilities that require immediate attention should be identified in the initial stage and then a set of questions for every such service or facility should be framed.

Although qualitative survey provides freedom and flexibility in providing the responses, these surveys are time consuming. Additionally they are difficult to compile andanalyse due to the absence of uniform answer options to choose from. Therefore a combination of qualitative and quantitative questions may be designed to fetch a multi- faceted student opinion.

Researchers have suggested several methods of obtaining the feedback. Some of the methods include observation, oral and informal feedback, questionnaires, student participation in institute level committees, online survey and so on. Every method has its own merits and demerits. A particular method or a combination of methods can be adopted depending on the situation and requirement of the institute.

4.3 Determining attributes of effective service / facility Institutions imparting higher education are

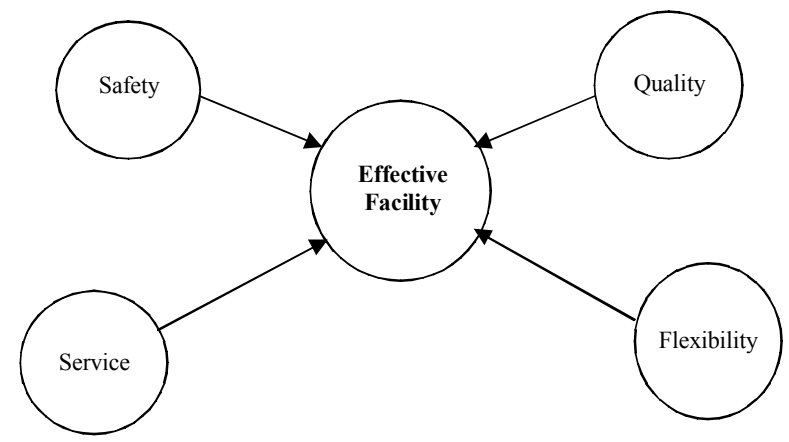

Fig. 1 : Attributes of effective facility now increasingly recognized as service industry and lay a greater emphasis on meeting the needs of the stakeholders (Sapri et al. 2009). A number of services and facilities are extended to the students of any institute and they mainly address quality, flexibility, service and safety related issues. These attributes are as shown in figure 1. Researchers may however consider inclusion of additional attributes to suit the purpose.

\subsection{Mapping feedback questions with attributes}

In this step, every question framed during the second stage of this approach can then mapped with the attributes determined for effective facility. A matrix structure can be prepared and average value of the student responses can be used to populate the evaluation matrix.

\subsection{Determining weights of the attributes}

The next important step in the process is determining weights for various attributes. Classification of weighs can be grouped in three categories namely subjective, objective and combined or integrated approach (Ginevicius and Podvezko 2005; Odu 2019). Researchers can employ a suitable method depending on the circumstances. These methods are discussed in brief as follows:

\subsubsection{Subjective methods:}

These methods for determining the weights are based on the knowledge; experience and opinion of the expert. Some of the commonly used subjective methods include equal weight method, point allocation method, direct rating method, pair-wise comparison method, digital logic method, ranking method, ratio method, swing method, delphi method, Nominal group technique and Simple Multi- attribute Rating Technique (SMART). Appropriate methods in the current context are discussed below:

\section{a. Pair-wise comparison:}

Analytic Hierarchy Process (AHP) is a well known Multi-criteria decision making (MCDM) technique based on measurement through pair-wise comparisons (Saaty 1980). This technique is effective in dealing with complex decision making process and helps to arrive at the best possible decision. Pair-wise comparison is an important stage in this technique. A relative measure is used to obtain pair-wise 
comparisons (Sebahat 2013). Based on the pair wise comparison, this method determines weights for every evaluation criteria. In order to reduce the bias in the process, a consistency check is also provided. If the consistency ratio is less than 0.1 then the evaluation of preferences are considered as appropriate (Joshi, et al., 2017a). A consistency ratio greater than 0.1 , indicates that pair-wise comparisons should be rechecked or revisited.

\section{b. Ratio method:}

In this method, ranks are assigned to the criteria according to their importance. The least important criterion is assigned the value of 10 . Thereafter the remaining criteria are assigned the value in multiples of 10 . The resulting weights are normalized so that the summation is equal to one.

\section{c. Delphi method:}

This method assumes that the group judgements are more accurate than the individual judgements or unstructured groups. In this method, questionnaires are provided to the experts of the group. After every round group facilitator provides the summary of the expert's opinion from the earlier round along with reason for their judgement. The group members then revise their judgements in light of the judgement of other members of the group. The process brings the members towards the correct answer and halts after a predetermined criteria. The mean score of the final round determine the result. Unlike brainstorming, this technique keeps the inputs anonymous thereby avoiding the impact of dominant individuals and peer pressure.

\section{d. Digital logic method:}

In this method two criteria are considered at a time. Every criterion is compared with rest of the criteria and relative performance is determined. The important criterion is assigned the value ' 1 ' while less important criterion is assigned the value ' 0 ' (DehghanManshadi et al. 2007). Total number of possible decisions is given by the following formulae:

$$
N=\frac{n(n-1)}{2}
$$

where $\mathrm{n}$ represents number of criteria
Weight for every criterion is obtained by dividing the total number of positive decisions for that criterion by the total number of possible decisions $(\mathrm{N})$.

\subsubsection{Objective methods:}

In an objective method mathematical functions (models) are employed to obtain the weights. In these methods expert opinion is not considered directly (Sahoo et al. 2016) and thus eliminates the interference of a decision maker. Some of the commonly used objective methods include mean weight method, entropy method, criteria impact loss method (CILOS), standard deviation method, statistical variance method and criteria importance through inter-criteria (CRITIC) method. Appropriate methods in the current context are discussed in brief:

\section{a. Mean weight method(MW):}

This method is normally used when the decision maker does not have enough information to arrive at a conclusion and assumes that all criteria have equal importance. Thus the weight is calculated by following formulae:

$$
W_{j}=\frac{1}{n}
$$

where $n$ represents the number of criteria

\section{a. Entropy method:}

The objective weights (wi) of alternatives using entropy method are calculated as:

$$
w_{i}=\frac{1-e_{j}}{\sum_{j=1}^{n}\left(1-e_{j}\right)}
$$

where entropy $e_{j}=-\frac{1}{\ln (m)} \sum_{i=1}^{m} r_{i j} \cdot \ln \left(r_{i j}\right)$;

$m$ represents the number of alternatives and

$n$ represents the number of criteria

The entropy method for determination of weight thus considers adequately the information of values all the alternatives provided to balance the relationship among numerous evaluating objects or criteria. This weakens the bad effect from some abnormal values and makes the result of evaluation more accurate and reasonable. The limitation of 
entropy method is that the relative values obtained for the criteria weights largely depend on the ratio of the highest value to the lowest values. When these ratios get higher, the weights of criteria also increase. However, when the ratios become very large, the weights do not change considerably

\section{c. Criteria impact loss method(CILOS):}

The CILOS method eliminates the drawback of the entropy method. When there is a criterion with very similar values, the elements of the relative loss matrix approaches zero, and the respective weights of the criteria are increased and strongly influence the evaluation. In the case of homogeneity, when a criterion has the same value for all alternatives, all relative losses and the overall loss (their sum total) are equal to zero. Formulation of CILOS method also shows that when a criterion has virtually the same value for all alternatives, its weight is close to one.

\subsubsection{Combined or integrated weighting methods:}

This method employs a mathematical model and combines both the subjective and objective factors for calculating the weights. This approach overcomes the limitations of both the methods especially when there are many alternatives with correlated criteria. determine the percentage contribution and ranking of alternatives. A couple of well known and commonly employed MCDM methods are discussed herein.

\subsection{Application of decision making method:}

Financial resources available with the managements of un-aided technical institutions are limited. Therefore fund allocation for upgrading various facilities should be carried out carefully. Several MCDM methods are available to

\subsubsection{Technique for Order of Preference by Similarity} to Ideal Solution (TOPSIS):

This method was initially developed by Hwang and Yoon (1981). Later on further developments were carried out by Yoon (1987) and Hwang et al. (1993). In this technique, the chosen alternative has shortest geometric distance from the positive-ideal solution (PIS) and farthest geometric distance from the negative-ideal solution (NIS). APIS maximizes the benefit criteria and minimize the cost criteria whereas NIS maximizes the cost criteria and minimizes the benefit criteria (Rao 2007; Joshi, et al., 2017b).This method can be categorized as multiattribute decision making technique having a limited number of pre specified objectives.

\subsubsection{Preference Ranking Organization METHod for Enrichment Evaluation(PROMETHEE):}

This technique was developed by Professor Brans in 1982. It was then developed and implemented in the year 1984 by Brans and Mareschal. The philosophy and application steps used in this method are simple as compared to the other methods (Goumas and Lygerou, 2000). The method provides ranking of alternatives and deals with the qualitative and quantitative criteria simultaneously.

\section{Results and discussion}

The approach discussed in section 4 was adopted to determine the distribution of available funds amongst the selected services and facilities of the institute. In the first step 14 facilities extended by the institution were identified. These have been discussed in subsection 4.1. As discussed in the methodology section, Google Form was used to obtain student opinion and shortlist facilities that require immediate attention.

Every question given in the second stage of the survey was mapped with the attributes determined for effective facility. A matrix structure was prepared and average value of the responses was used to populate the matrix. The matrix so obtained by mapping the attributes with the services and facilities shortlisted in the second stage of the survey is shown in table 2.

The institute under consideration gave equal importance to all services and facilities. Hence mean weight method was adopted and accordingly uniform weight (i.e. 0.25) was assigned to every attribute. The weighted normalized matrix thus obtained is shown in table 3 .

Table 2 : Mapping of services/facilities with attributes

\begin{tabular}{ccccc}
\hline \multirow{2}{*}{ Service / Facility } & \multicolumn{4}{c}{ Attributes } \\
\cline { 2 - 5 } & Quality & Service & Flexibility & Safety \\
\hline Internet & 4.079 & 4.023 & 3.049 & 3.387 \\
Hostel & 3.994 & 4.143 & 3.734 & 4.265 \\
Mess & 4.51 & 3.867 & 4.19 & 3.697 \\
Parking & 3.797 & 3.043 & 3.717 & 3.659 \\
\hline
\end{tabular}


The institute under consideration gave equal importance to all services and facilities. Hence mean weight method was adopted and accordingly uniform weight (i.e. 0.25 ) was assigned to every attribute. The weighted normalized matrix thus obtained is shown in table 3.

Table 3 : Weighted Normalized Matrix $($ Weight $=0.25)$

\begin{tabular}{ccccc}
\hline \multirow{2}{*}{$\begin{array}{c}\text { Elements / } \\
\text { Alternatives }\end{array}$} & \multicolumn{4}{c}{ Attributes } \\
\cline { 2 - 5 } & Quality & Service & Flexibility & Safety \\
\hline Internet & 0.124 & 0.132 & 0.103 & 0.112 \\
Hostel & 0.121 & 0.136 & 0.126 & 0.141 \\
Mess & 0.137 & 0.127 & 0.141 & 0.122 \\
Parking & 0.115 & 0.100 & 0.125 & 0.121 \\
\hline
\end{tabular}

By employing the equation no. 6 given in the methodology section, rank and percentage contribution of every alternative was obtained and is shown in table 4.

Table 4 : Percentage Contribution and Ranking of Alternatives

\begin{tabular}{ccc}
\hline Elements / Alternatives & Percentage Contribution & Rank \\
\hline Internet & 0.186 & 3 \\
Hostel & 0.328 & 2 \\
Mess & 0.333 & 1 \\
Parking & 0.153 & 4 \\
\hline
\end{tabular}

In view of the limited resources available at the disposal, it is necessary for the management of the institute to understand the proportion in which the available funds should be distributed amongst the shortlisted services or facilities.

Proportion of fund allocation obtained by dividing value of individual attribute by summation of attribute for every given element / alternative of the evaluation matrix is shown in table 5 .

Table 5 : Proportion of fund allocation for every attribute

\begin{tabular}{ccccc}
\hline \multirow{2}{*}{$\begin{array}{c}\text { Elements } / \\
\text { Alternatives }\end{array}$} & Quality & Service & Flexibility & Safety \\
\cline { 2 - 5 } & Attributes \\
\hline Internet & 28.0575 & 27.67231 & 20.97262 & 23.29757 \\
Hostel & 24.75211 & 25.67551 & 23.1408 & 26.43158 \\
Mess & 27.72996 & 23.77644 & 25.76242 & 22.73119 \\
Parking & 26.70934 & 21.40546 & 26.1466 & 25.7386 \\
\hline
\end{tabular}

Finally the actual fund allocation for every attribute of a given element / alternative was calculated. This was done by multiplying the proportionate fund allocation for every attribute (as shown in table 5) with the percentage contribution of respective element / alternative (as shown in table 4). The actual per rupee (fund) allocation for every attribute thus obtained is shown in table 6 .

Table 6 : Fund allocation for every attribute per Indian Rupee

\begin{tabular}{ccccc}
\hline \multirow{2}{*}{$\begin{array}{c}\text { Elements / } \\
\text { Alternatives }\end{array}$} & Quality & Service & Flexibility & Safety \\
\cline { 2 - 5 } Internet & 0.052187 & 0.05147 & 0.039009 & 0.043333 \\
Hostel & 0.081187 & 0.084216 & 0.075902 & 0.086696 \\
Mess & 0.092341 & 0.079176 & 0.085789 & 0.075695 \\
Parking & 0.040865 & 0.03275 & 0.040004 & 0.03938 \\
\hline
\end{tabular}

Results indicate that quality attribute of 'Mess' is the crucial issue which needs significant improvement and hence maximum funds should be allotted to this criterion. At the same time it is observed that service attribute of 'Parking' is the least significant issue and therefore minimum funds can be allotted for this aspect.

The results obtained from the study show how every single Indian rupee allocated for improving the institutional facilities can be distributed amongst the criteria of every alternative under consideration. It appears that the fund allocation for different attributes is almost same irrespective of the type of service or facility and is shown in figure 2 .

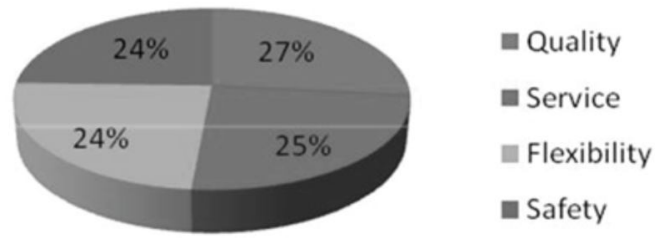

Fig. 2 : Percentage fund allocation for different attributes

So far as the services / facilities are concerned, it is observed that Mess and Hostel are the areas requiring significant improvement as indicated in figure 3 .

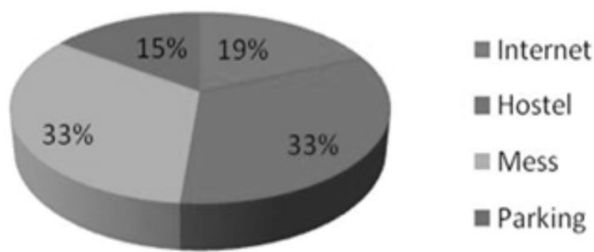

Fig. 3 : Percentage fund allocation for different alternatives / facilities 


\section{Conclusion}

Institutes are keen to upgrade every facility extended to the students. Considering the limited funds available at the disposal, it is necessary to prioritize the facilities to be upgraded. The above study offers a low cost effective mechanism to prioritize the facilities to be upgraded based on user perception and fund allocation for every criterion within the selected facility or alternative. This exercise will not only help to upgrade the student facilities in a phased manner but also boost the morale of students thereby enhancing the brand image of the institute.

Students feel that every attribute irrespective of the type of service or facility should be addressed by the institute. Quality attribute of the Mess is an area that requires significant improvement. Various subattributes of all the attributes considered in the study have already been taken into account during the second survey. Students seem to be satisfied with the Parking facility. This is due to the fact that good parking facility is provided by the institute and the availability of good public transport system.

The proposed methodology can be well adopted by other technical institutes by considering their own services and facilities.

This study however suffers from some limitations. Other support facilities such as ambience and number of lecture / practical halls, adequacy of equipments, availability of sanitation facilities, on campus security and ERP support have not been covered. A detailed study covering all aspects available in the institution can be undertaken. In spite of these limitations, authors believe that this study has been able to develop an effective mechanism to set the priority for upgrading various facilities and allocate funds in an appropriate manner.

\section{References}

[1] Angadi, S. S. and Ravanavar, G. M. (2014), A study and analysis of training and placement cells in engineering colleges, International Journal of Management, IT and Engineering, 4(10), pp. 162-175.

[2] Babakus, E. and Mangold, W. G. (1992), Adapting the SERVQUAL scale to hospital services: an empirical investigation, Health services research, 26(6), pp. 767-786.

[3] Chaubey, A. and Manglik, D. (2017), Use of Library Facilities and Resources by Research Scholar at Guru Ghasidas University, Bilaspur, Chhattisgarh: A case study, International Journal of Library and Information Studies, 7(2), pp. 110 .

[4] Chiguvi, D. and Ndoma, J. T. (2018), The Effects of Shortage of Accommodation on Students' Performance in Private Tertiary Institutions in Botswana, Journal of Economics and Sustainable Development, 9(4),pp. 97- 104.

[5] Choudhury, K. (2015), Evaluating customerperceived service quality in business management education in India, Asia Pacific Journal of Marketing and Logistics, 27(2), pp. 208-225.

[6] Ciobanu, A. (2013), The Role of Student Services in the Improving of Student Experience in Higher Education, Procedia - Social and Behavioral Sciences, 92, pp. 169-173. doi: 10.1016/j.sbspro.2013.08.654

[7] Coskun, L. (2014), Investigating the Essential Factors on Student Satisfaction: A Case of Albanian Private University, Journal of Educational and Social Research, 4(1), pp. 489503.

[8] Dada, R. M., Oladapo, O. S. and Olayiwola, M. M. (2018), Influence of educational facilities maintenance practices on quality assurance in public higher institutions in Lagos State, Nigeria, Global Journal ofCommerce \& Management Perspective, 7(2), pp. 51-54.

[9] Dehghan-Manshadi, B., Mahmudi, H., Abedian, A. and Mahmudi, R. (2007), A novel method for materials selection in mechanical design: Combination of non- linear normalization and a modified digital logic method, Materials and Design, 28(1), pp. 8-15.

[10] Ginevicius, R. and Podvezko, V. (2005), Objective and subjective approaches to determining the criterion weight in multicriteria models, Proceedings of International 
Conference RelStat'04 Transport and Telecommunication, 6(1), pp. 133-137.

[11] Godstime, T. C. and Joseph, A. O. (2019), Influence of school environment on students' academic performance in technical colleges in Rivers State, International Journal of New Technology and Research, 5(3), pp. 40-48.

[12] Goumas, M. and Lygerou, V. (2000), An extension of the PROMETHEE method for decision making in fuzzy environment: Ranking of alternative energy exploitation projects, European Journal of Operational Research, 123(3), pp. 606-613.

[13] Hwang, C. L. and Yoon, K. (1981), Multiple Attribute Decision Making: Methods and Applications: a state- of-the-art survey, Springer-Verlag, New York.

[14] Hwang, C. L., Lai, Y. J. and Liu, T. Y. (1993), A New Approach for Multiple Objective Decision Making, Computers and Operational Research, 20(8), pp. 889-899.

[15] Isa, A., Wan, Z. W. Y. and Emmanuel, G. (2017), A Review of Physical and Non-Physical Facilities Performance on Student Satisfaction in Northen Nigerian Universities, The Social Sciences, 12(4), pp. 600-608.

[16] Joshi, A. S., Deshpande, V. S. and Pawar, P. J. (2017a), Identification of factors influencing the performance of government organizations and undertakings in India using analytic hierarchy process, International Journal of Services Sciences, 6(2), pp.162-176.

[17] Joshi, A. S., Deshpande, V. S. and Pawar, P. J. (2017b), An application of TOPSIS for selection of appropriate e-Governance practices to improve customer satisfaction, Journal of Project Management, 2(3), pp. 93-106.

[18] Joshi, A. S., Deshpande, V. S. and Pawar, P. J. (2019), Evaluating the effect of organizational practices on work effectiveness of employees, International Journal of Management Concepts and Philosophy, 12(2), pp. 133-149.

[19] Kannappanavar and Jayaprakash (2014), Library Facilities, Sources and Services in the
Engineering Colleges in Goa State: A Study, International Journal of Librarianship and Administration, 5(2), pp. 131-146.

[20] Kaur, S. (2016), Student Support Services in Higher Education: A Student Perspective, The International Journal of Indian Psychology, 3(3) No. 9, pp. 126-132.

[21] Khozaei, F., Ayub, N., Hassan, A. S., and Khozaei, Z. (2010), The Factors Predicting Students' Satisfaction with University Hostels, Case Study, Universiti Sains Malaysia, Asian Culture and History, 2(2), pp. 148- 158.

[22] Lohar, M. S. and Kumbhar, M. (2002), Use of Library Facilities and Information Resources in Sahyadri Colleges, Shimoga (Karnataka): A Study, Annals of Library and Information Studies, 49(3), pp. 73-87.

[23] Maddock, B., Warren, C. and Worsley, A. (2005), Survey of canteens and food services in Victorian schools, Nutrition \& Dietetics, 62(23),pp. 76-81.

[24] Moate, K. M., Chukwuere, J. E. and Mavhungu, M. B. (2017), The impact of wireless fidelity on students' academic performance in a developing economy, 31stInternational Academic Conference London, pp. 139-155. doi: 10.20472/IAC.2017.031.032

[25] Mondal, R., Sarkar, B. and Sarkar, B. (2018), Learning Environment of Hostel \&Mess at PG level - A Comparison, International Journal of Interdisciplinary Research and Innovations, 6(3), pp. 373-377.

[26] Musa, M. F. and Baharum, Z. A. (2012), Higher Education Physical Assets and Facilities, Procedia - Social and Behavioral Sciences, 50, pp. $472-478$.

[27] Nepal, B. (2016), Relationship among school's infrastructure facilities, learning environment and student's outcome, International Journal for Research in Social Science and Humanities Research, 2(5), pp. 44-57.

[28] Nepal, B. and Maharjan, R. (2015), Effect of school's physical facilities on learning and outcomes of students in Nepal, Journal for 
Studies in Management and Planning, 1(6), pp. 266-279.

[29] Newmon, M. and Sengar, V. (2013), Engineering College Library, International Journal of Advanced Research in Computer Science and Software Engineering, 6(3), pp. 615-618.

[30] Norman, G. (2019), Canteen Service Quality and Student Satisfaction, International Journal of Scientific \& Technology Research, 8(6), pp. 114-126.

[31] Obeidat, A. and Al-Share, R. (2012), Quality Learning Environments: Design-Studio Classroom, Asian Culture and History, 4(2), pp. 165-174.

[32] Odeh, R. C., Oguche, O. A. and Ivagher, E. D. (2015), Influence of School Environment on Academic Achievement of Students in Secondary Schools in Zone "A" Senatorial District of Benue State Nigeria, International Journal of Recent Scientific Research, 6(7), pp. 4914-4922.

[33] Odu, G. O. (2019), Weighting Methods for Multi- Criteria Decision Making Technique, Journal of Applied Sciences and Environmental Management, 23(8), pp. 1449-1457.

[34] Patel, V., Patel, H., Gupta, S. and Shah, B. (2014), online report on Effectiveness of Transportation / Escorts on Regularity, Retention and Academic Achievement of the Students, carried out under Sarva Shiksha Abhiyan, $\quad \mathrm{h} \mathrm{t} \mathrm{t} \mathrm{p} \mathrm{:} \mathrm{/} \mathrm{/} \mathrm{g} \mathrm{u} \mathrm{j} \mathrm{a} \mathrm{r} \mathrm{a} \mathrm{t} \mathrm{-}$ education.gov.in/ssa/images/Final_Project_Rep $\operatorname{ort}(\mathrm{KS} \mathrm{V})$.pdf (last accessed on 30 th October 2019).

[35] Philip, A., Ileanwa, A. C. and El-Hussain, A. M. (2018), Post-Occupancy Evaluation of Students Hostel Facilities in Federal Universities in North Central, Nigeria, Architecture Research, 8(4), pp. 123-128.

[36] Pradeepkumar and Mohana, P. (2017), Students' behavior of rural colleges towards the internet, International Journal of Advanced Research, 5(9), pp. 861-865.
[37] Rani, P. (2018), A Study on Library Resources with Services Satisfaction Based on Students and Faculties: In an Institution, International Journal of Applied Engineering Research, 13(22), pp. 15443-15450.

[38] Rao, R. V. (2007), Decision making in the manufacturing environment: using graph theory and fuzzy multiple attribute decision making methods, Springer-Verlag, London.

[39] Reale, A. (2000), University food services: Student dining expectations, needs and wants versus what is actually received in a mid-size university, Master's thesis at Rochester Institute of Technology.

[40] Rotaris, L. and Danielis, R. (2015), Commuting to college: The effectiveness and social efficiency of transportation demand management policies, Transport Policy, 44, pp. 158-168.

[41] Sapri, M., Kaka, A. and Finch, E. (2009), Factors that influence student's level of satisfaction with regards to higher educational facilities services, Malaysian Journal of Real Estate, 4(1), pp. 3451.

[42] Saaty, T. L. (1980), The Analytic Hierarchy Process, New York: McGraw-Hill.

[43] Sebahat, Y. (2013), Analysis of analytic hierarchy process of some algebra factors affecting the field concept over a commutative ring with identity element definition, Life Science Journal, 10(5), pp. 328-339.

[44] Sahoo, M., Sahoo, S., Dhar, A. and Pradhan, B. (2016), Effectiveness evaluation of objective and subjective weighting methods for aquifer vulnerability assessment in urban context, Journal of Hydrology, 541(Part B), pp. 13031315. doi: 10.1016/j.jhydrol.2016.08.035.

[45] Selvaraja, A., Asha, P. and Jayakumar. (2014), Use of Wi-Fi connection by the research scholars of University of Mysore, Karnataka: a study, International Journal of Academic Library and Information Science, 2(10), pp. 150-157. doi: 10.14662/IJALIS2014.041 
[46] Shahabadkar, P., Joshi, A. and Nandurkar, K. (2019), Developing IT Enabled Mechanism for SWOC Analysis: A Case Study, Proc. of the 2nd International Conference on Manufacturing Excellence (ICMAX- 2019), pp. 158-164. ISBN: 978-93-88441-69-8

[47] Sharma, B., Tekchandani, S. and Afreen, S. (2018), Impact of Hostel Life on Personality Development and Self Management Skills amongst Female Students in Rajasthan, Research Review International Journal of Multidisciplinary, 3(9), pp. 512-518.

[48] Singh, Vaishali. and Kumar, Ravindra. (2017), A study of the impact of institutions' infrastructural facilities and teaching-learning resources on academic attainments and placements of management students, International Journal of Development Research, 7(11), pp. 1729817306.

[49] Stewart, B. L., Goodson, C. E., Miertschin, S. L., Norwood, M. L. and Ezell, S. (2013), Online Student Support Services: A Case Based on Quality Frameworks, MERLOT Journal of
Online Learning and Teaching, 9(2), pp. 290303.

[50] Suki, N. M. and Chowdhury, I. A. (2015), Students' Attitude and Satisfaction Living in Sustainable On- Campus Hostels, Malaysian Journal of Business and Economics, 2(1), pp. 35-47.

[51] Tsedzah, V. A. and Obuobisa-Darko, T. (2015), Assessing Students' Satisfaction: An Approach to Help

Improve Services Rendered to University Students, European Journal of Business and Management, 7(5), pp. 115-122.

[52] Weerasinghe, M. C., Bandara, S. and Sanoon, M. (2017), Service quality of school canteens: a case study from the Western Province, Sri Lanka, Ceylon Journal of Medical Science, 54(2), pp. 11-16.

[53] Yoon, K. (1987), A Reconciliation Among Discrete Compromise Situations, Journal of Operational Research Society, 38(3), pp. 277286. 